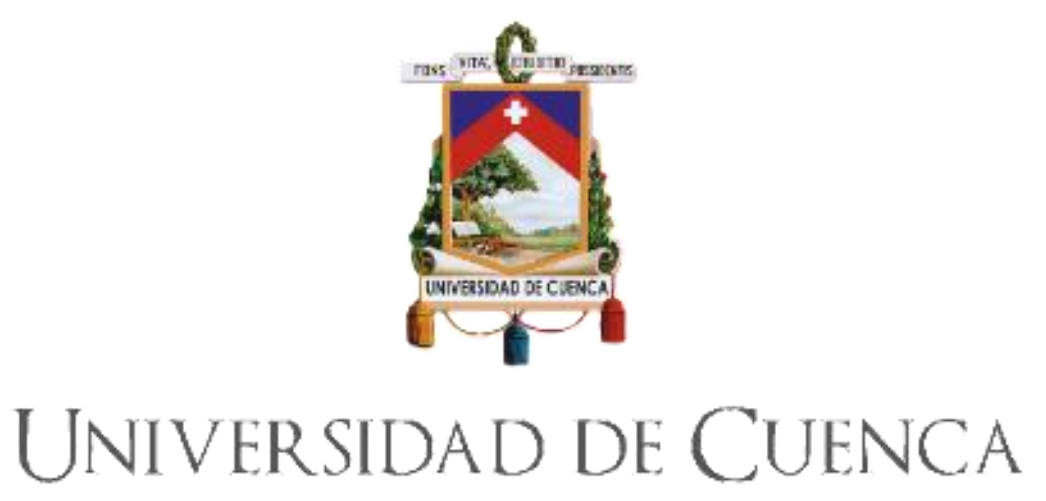

Facultad de Ciencias Médicas

Posgrado en Pediatría

\title{
PREVALENCIA DE NEUMONÍA COMPLICADA EN PACIENTES PEDIÁTRICOS HOSPITALIZADOS EN EL HOSPITAL JOSÉ CARRASCO ARTEAGA. ENERO DEL 2014 A DICIEMBRE DEL 2017
}

Tesis previa a la obtención del título de Especialista en Pediatría

\section{Autora:}

Md. Verónica Katherine Sánchez Ordóñez

$\mathrm{Cl}: 1104877327$

vero.sanchez_17@hotmail.com

Director:

Dr. Giovanni Paolo González Pazmiño

Cl: 0102680493

Cuenca - Ecuador

06-Marzo-2020 


\section{RESUMEN}

ANTECEDENTES: La neumonía complicada representa un problema de salud en la población pediátrica, forma parte de las enfermedades respiratorias agudas, siendo la principal causa de morbimortalidad hospitalaria, siendo necesario el diagnóstico y tratamiento oportuno.

OBJETIVO: Determinar la prevalencia de neumonía complicada en los pacientes hospitalizados del servicio de Pediatría del Hospital "José Carrasco Arteaga" de la ciudad de Cuenca de enero del 2014 a diciembre del 2017

METODOLOGÍA: Estudio descriptivo transversal en pacientes del área de Pediatría y Cuidados Intensivos Pediátricos desde enero del 2014 a diciembre del 2017. Para el análisis se utilizó la estadística descriptiva, los datos fueron tabulados en el programa SPSS v.15.

RESULTADOS: La prevalencia de neumonía complicada es de $28,8 \%$. Hubo predominio del sexo masculino con $56.4 \%$, así como del grupo etario de 0 a 3 años con $43.6 \%$ y la población proviene en su mayoría de la zona urbana en $58,9 \%$. Se encontró desnutrición en el $51.1 \%$, las comorbilidades más comunes fueron las respiratorias con $12.4 \%$. La mayoría requirió hospitalización por 5-9 días representando $54,6 \%$, los antibióticos más utilizados fueron los betaláctamicos en el $85.8 \%$ de los casos. La complicación más frecuente fue la bacteremia en $43,2 \%$ y la mortalidad alcanzó el $8.1 \%$.

CONCLUSIONES: La prevalencia de la neumonía complicada es elevada, con predominio de la bacteremia, en el sexo masculino, en menores de 3 años, con desnutrición, el antibiótico que más se utilizó fueron los betalactamicos.

PALABRAS CLAVE: Neumonía. Complicaciones. Pediatría.

Md. Verónica Katherine Sánchez Ordóñez 


\section{ABSTRACT}

BACKGROUND: Complicated pneumonia represents a health problem in the pediatric population, is part of acute respiratory diseases, being the main cause of hospital morbidity and mortality, the diagnosis and timely treatment being necessary.

OBJECTIVE: To determine the prevalence of complicated pneumonia in hospitalized patients of the Pediatric Department of the "José Carrasco Arteaga" Hospital in the city of Cuenca from January 2014 to December 2017

METHODOLOGY: Descriptive cross-sectional study in patients in the area of Pediatrics and Pediatric Intensive Care from January 2014 to December 2017. For the analysis, descriptive statistics were used, the data were tabulated in the SPSS v.15 program.

RESULTS: The prevalence of complicated pneumonia is $28.8 \%$. There was a predominance of the male sex with $56.4 \%$, as well as the age group of 0 to 3 years with $43.6 \%$ and the population comes mostly from the urban area at $58.9 \%$. Malnutrition was found in $51.1 \%$, the most common comorbidities were respiratory with $12.4 \%$. The majority required hospitalization for $5-9$ days, representing $54.6 \%$, the most commonly used antibiotics were the betaláctamicos in $85.8 \%$ of the cases. The most frequent complication was bacteremia in $43.2 \%$ and mortality reached $8.1 \%$.

CONCLUSIONS: The prevalence of complicated pneumonia is high, with a predominance of bacteremia, in males, in children under 3 years of age, with malnutrition, the most commonly used antibiotic was beta-lactam.

KEY WORDS: Pneumonia. Complications. Pediatrics. 


\section{INDICE}

Contenido:

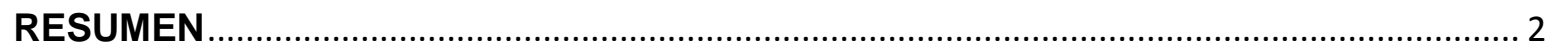

ABSTRACT

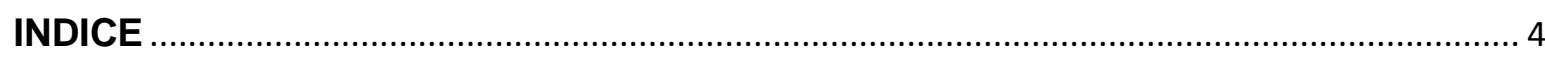

AGRADECIMIENTO

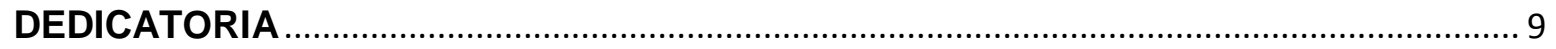

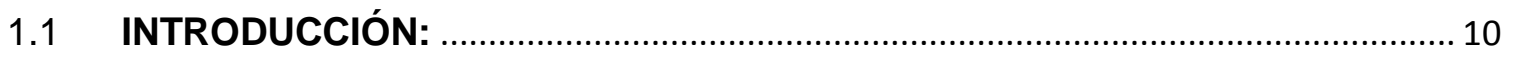

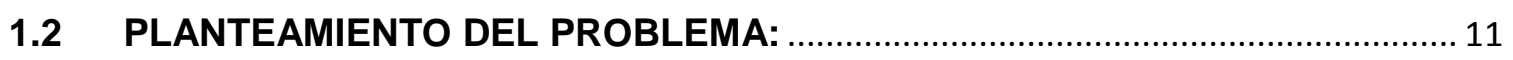

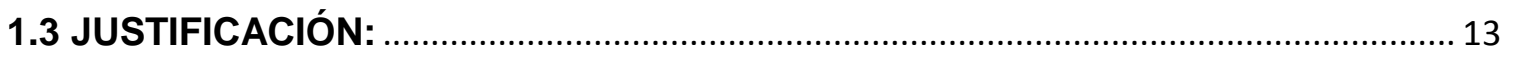

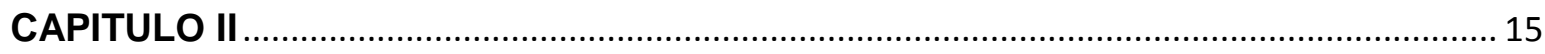

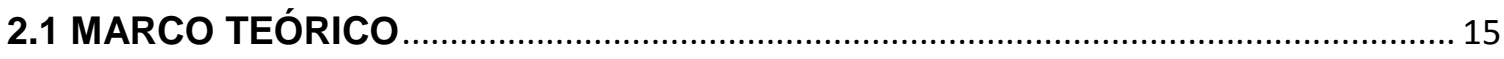

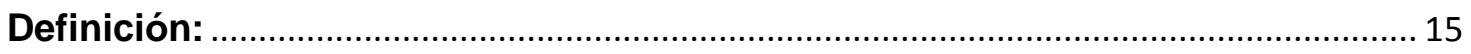

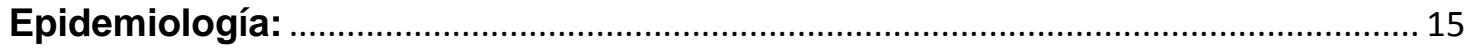

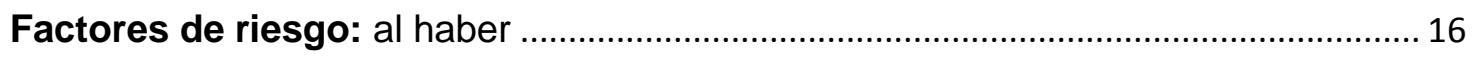

Etiología:

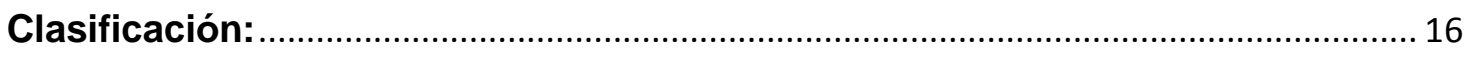

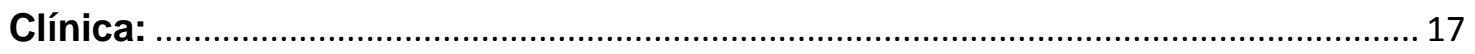

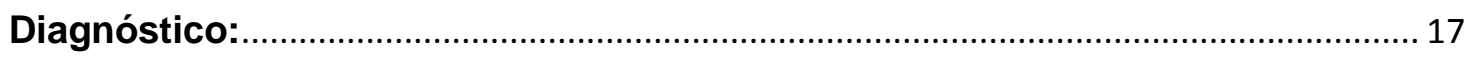

Complicaciones de la neumonía ....................................................................... 18

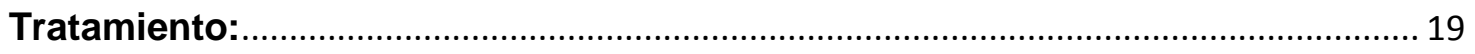

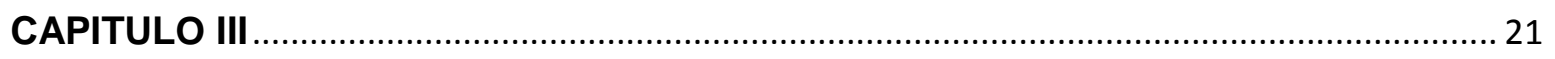

3.1 OBJETIVOS:

3.1.1. GENERAL:

1.1.2. ESPECÍFICOS:

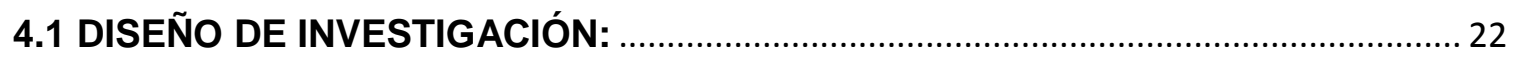

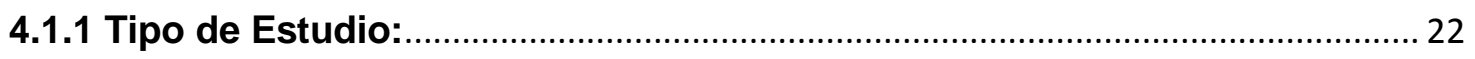

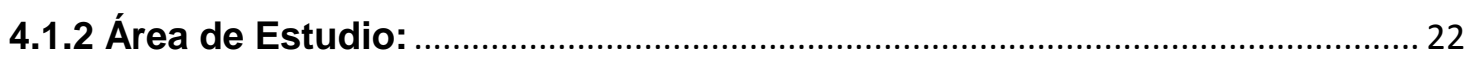

4.1.3 Universo de estudio: ................................................................................... 22

Md. Verónica Katherine Sánchez Ordóñez 


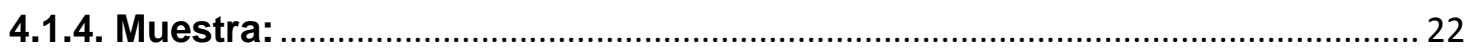

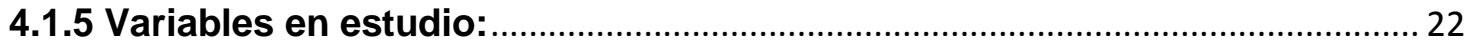

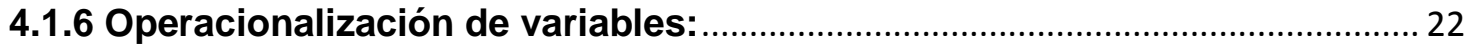

4.1.7 Criterios de inclusión:

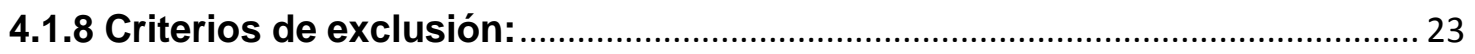

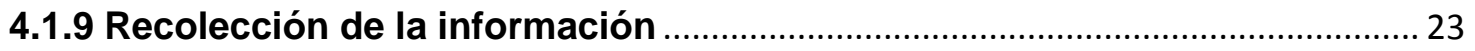

4.1.10 Aspectos éticos:

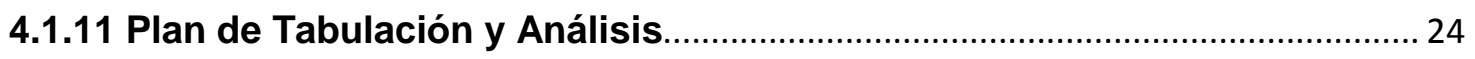

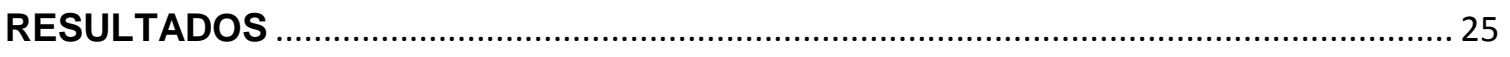

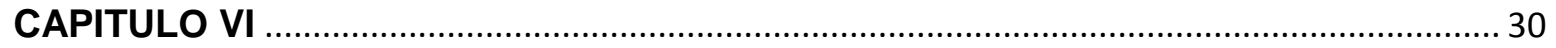

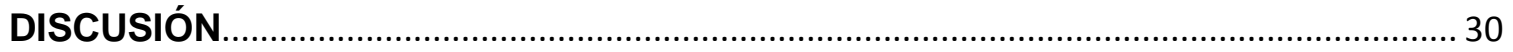

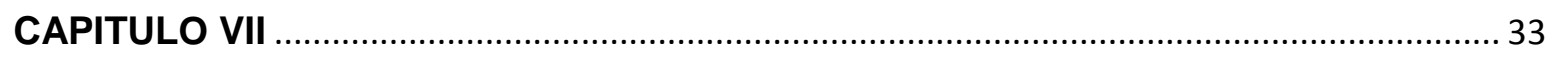

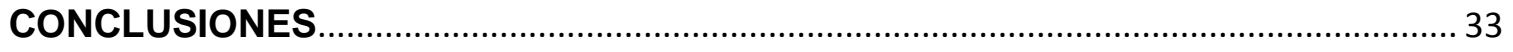

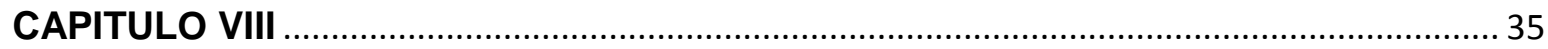

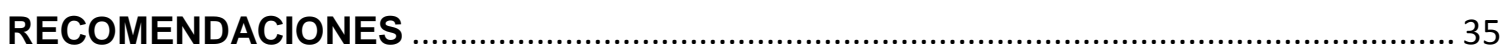

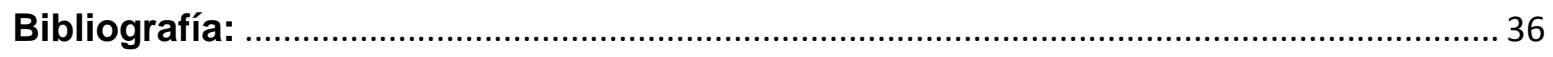

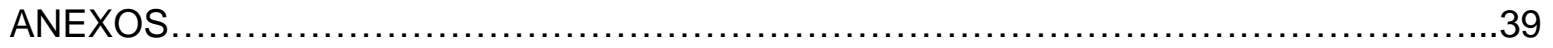

Md. Verónica Katherine Sánchez Ordóñez 


\section{Cláusula de licencia y autorización para publicación en el Repositorio} Institucional

Verónica Katherine Sánchez Ordóñez en calidad de autora y titular de los derechos morales y patrimoniales de la tesis PREVALENCIA DE NEUMONÍA COMPLICADA EN PACIENTES PEDIÁTRICOS HOSPITALIZADOS EN EL HOSPITAL JOSÉ CARRASCO ARTEAGA. ENERO DEL 2014 A DICIEMBRE DEL 2017, de conformidad con el Art. 114 del CÓDIGO ORGÁNICO DE LA ECONOMÍA SOCIAL DE LOS CONOCIMIENTOS, CREATIVIDAD E INNOVACIÓN reconozco a favor de la Universidad de Cuenca una licencia gratuita, intransferible y no exclusiva para el uso no comercial de la obra, con fines estrictamente académicos.

Así mismo, autorizo a la Universidad de Cuenca para que realice la publicación de esta tesis en el repositorio institucional, de conformidad a lo dispuesto en el Art. 144 de la Ley Orgánica de Educación Superior.

Cuenca, 06 de marzo del 2020

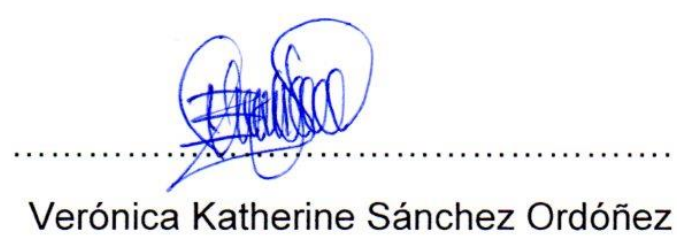

Cl: 1104877327 


\section{Cláusula de propiedad intelectual}

Verónica Katherine Sánchez Ordóñez, autora de la tesis PREVALENCIA DE NEUMONÍA COMPLICADA EN PACIENTES PEDIÁTRICOS HOSPITALIZADOS EN EL HOSPITAL JOSÉ CARRASCO ARTEAGA. ENERO DEL 2014 A DICIEMBRE DEL 2017. Certifico que todas las ideas, opiniones y contenidos expuestos en la presente investigación son de exclusiva responsabilidad de su autora.

Cuenca, 06 de Marzo del 2020

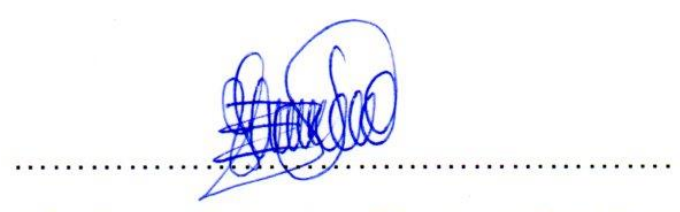

Verónica Katherine Sánchez Ordóñez

Cl: 1104877327

\section{AGRADECIMIENTO}

Md. Verónica Katherine Sánchez Ordóñez 
A Dios, por darme la oportunidad de crecer tanto como profesional y como persona, por haberme regalado este sueño tan anhelado.

A mis docentes durante este proceso de posgrado, quienes me ayudaron y me enseñaron muchas cosas para el camino que ahora se nos abre.

A mi director de tesis: Dr. Giovanni González

A mi asesor de tesis: Dr. Luis Marcano

Sin ayuda no hubiera sido posible la realización del presente trabajo de investigación.

A mi familia por su apoyo incondicional durante estos 3 años, lejos de casa, pero en mi corazón y en mi mente siempre.

Y a mis compañeros y amigos de posgrado, con quienes luchamos día a día para que este sueño se haga realidad. 


\section{DEDICATORIA}

A mis queridos padres, Ruth y Miguel, por su apoyo incondicional, por su fortaleza y sacrificio por cumplir cada uno de mis sueños, por inculcarme valores y hacer de mi lo que soy ahora.

A mis hermanos, Cristina y Daniel, por ser mi alegría, mi pilar para seguir adelante, por darme ánimos cuando parecía que todo se derrumbaba y hacerme sonreír con su amor y ocurrencias.

A mi esposo Danny, por ser quien me impulsó a cumplir este sueño que hoy es una realidad, por apoyarme, y ayudarme cuando más lo necesite.

A mis abuelitos en el cielo y en la tierra por ser mis ángeles.

A mi familia por alentarme a seguir y cumplir mis metas, por estar pendientes de mí siempre.

A mis compañeros y amigos de posgrado por esta lucha diaria, por las sonrisas, las lágrimas, los momentos vividos y las enseñanzas, por ser mi apoyo en esta ciudad lejos de mi casa, y llegar a ser mi familia.

Md. Verónica Katherine Sánchez Ordóñez 


\section{CAPITULO I}

\subsection{INTRODUCCIÓN:}

La neumonía adquirida en la comunidad (NAC) representa la primera causa de muerte infantil a nivel mundial y una de las principales de morbilidad en los países desarrollados. La Organización Mundial de Salud (OMS) menciona que es responsable aproximadamente $19 \%$ de muertes en niños de menos de 5 años ${ }^{(1)}$.

La Asociación Española de Pediatría, la define como la infección aguda del parénquima pulmonar. Se caracteriza por presentar fiebre y/o síntomas respiratorios, junto con infiltrados pulmonares en la radiografía de tórax, el agente etiológico depende de la edad, en menores de 3 semanas, los gérmenes característicos del canal de parto, de 3 semanas a 3 meses son comunes los virus respiratorios, de 3 meses a 4 años lo más frecuente son los virus también, seguidos de Streptococo pneumoniae y por último en mayores de 5 años los más importantes son el Mycoplasma pneumoniae y Streptococo pneumoniae (2).

La neumonía típica es causante de la mayor morbilidad y mortalidad, es producida por distintas bacterias (Streptococcus pneumoniae, Haemophilus influenzae, Staphylococcus aureus, Streptococcus pyogenes y Klebsiella pneumoniae) ${ }^{(3)}$.

El Streptococcus pneumoniae es el patógeno principal en la neumonía típica, con mucha diferencia con respecto a otras bacterias, sobre todo en países en vías de desarrollo sigue siendo el responsable de gran parte de las complicaciones. Además, aparecen casos de neumonía por Staphylococcus aureus meticilinoresistentes que, junto con el Streptococcus pyogenes provocan neumonías muy agresivas con rápido desarrollo de empiema, abscesos y sepsis ${ }^{(3)}$.

La diferencia entre los distintos tipos de neumonías radica en los hallazgos producidos por el microorganismo que las ha provocado. El Staphylococcus se relaciona con la presencia de imágenes que se comparan con bolsas de aire sobre

Md. Verónica Katherine Sánchez Ordóñez 
todo en el lóbulo superior, en tanto la Klebsiella, presenta gran compromiso en el lóbulo inferior, con expectoración en "jarabe de grosellas" (4).

Las neumonías complicadas constituyen un grupo importante dentro de los ingresos a nuestros hospitales con patología torácica y se presentan como lesiones broncopulmonares y pleurales

complejas. Cuando la neumonía no se ha limitado al parénquima pulmonar sino que se ha extendido a las pleuras y se produce un empiema, se modifica notoriamente el curso clínico así como el pronóstico, siendo éste un reto para su correcto manejo, ya que no existe unificación en los criterios de clasificación lo que conlleva a retraso en la toma de decisiones así como su oportuno y adecuado tratamiento. Las mayores complicaciones de la neumonía están: fístula broncopleural, neumonía necrosante, neumotórax, y empiema ${ }^{(5)}$.

En la actualidad existe una preocupación general entre los pediatras acerca del aumento de casos de neumonía complicada. La misma que no es exclusiva de países en proceso de desarrollo sino de la población en general, he ahí la importancia de desarrollar estudios que indiquen valores reales sobre la prevalencia de este tipo de neumonías que llegan a complicarse e incluso causar la muerte.

\subsection{PLANTEAMIENTO DEL PROBLEMA:}

La neumonía es la primera causa de morbilidad y mortalidad principalmente en los países en vías de desarrollo. Según la Organización Mundial de la Salud, es causa de aproximadamente el 19\% de todas las muertes en menores de 5 años, produciendo 156 millones de casos por año y 20 millones de casos graves que requirieron hospitalización. En los países desarrollados la incidencia por año es 33

Md. Verónica Katherine Sánchez Ordóñez 
por 10.000 niños menores de 5 años y 14,5 por 10.000 niños entre los 0 y 16 años. La neumonía complicada representa $4 \%$ de ingresos y $1 \%$ de pacientes con manejo ambulatorio (1).

En Latinoamérica y el Caribe se estima que por año mueren más de 80.000 niños de menos de cinco años a causa de infecciones respiratorias bajas; entre ellas un $85 \%$ son debidas a neumonías complicadas. Esta mortalidad llega a representar en ciertos países, más del $20 \%$ de las muertes en este grupo de edad (6).

A nivel nacional, en el 2013 estudios realizados por el INEC señalaron que, dentro de las causas de mortalidad infantil, el tercer lugar lo ocupó la neumonía. Si bien es cierto es una patología cuyos casos han aumento en los últimos años según datos del Ministerio de Salud Pública (MSP). No se cuenta al momento con datos estadísticos de casos de neumonía complicadas en edad escolar, si hay datos de la población en general (7).

En Cuba la neumonía y sus complicaciones constituyeron la segunda causa de muerte en el año 2017, con una tasa de 0.5 por 10000 habitantes en menores de 5 años y en menores de un año ocupó el tercer lugar con una tasa de 0,2 por 1000 nacidos vivos. Además, constituyó la tercera causa de muerte en el mismo año en menores de un año con una tasa de 0,2 por 1000 nacidos vivos, y la segunda causa de muerte en niños de 1-4 años, con una tasa de 0,5 por 10000 habitantes ${ }^{(8)}$.

Se da cuando la evolución de la enfermedad no es buena, el cuadro infeccioso se ha esparcido a otras áreas yendo más allá del tejido pulmonar o la clínica inicial ha sido modificada por todo lo mencionado, lo cual representa un desafío para su manejo, esto provocado por la falta de unificación en criterios acerca de su tratamiento ${ }^{(11)}$.

Las complicaciones más comunes incluyen: derrame pleural, sepsis, abscesos pulmonares, empiema o fístulas broncopulmonares, siendo factores de riesgo para 
estas: el tabaquismo familiar, edad menor de 1 año, desnutrición, analfabetismo materno, hacinamiento y comorbilidades respiratorias, cardiacas o renales ${ }^{(5)}$.

Uno de los pilares fundamentales en la prevención de estas complicaciones es la descripción de la frecuencia, así como de las características clínicas del paciente con neumonía complicada, lo cual nos permite un diagnóstico precoz, así como un abordaje efectivo de las mismas, evitando de esta manera desenlaces fatales. Actualmente en nuestro medio, hay pocos estudios acerca de este tema a pesar de que no es una patología ajena a nuestros hospitales, por lo cual nos planteamos la siguiente pregunta de investigación ¿Cuál es la prevalencia de neumonía complicada en pacientes pediátricos hospitalizados en el Hospital José Carrasco Arteaga. Enero del 2014 a diciembre del 2017?

\subsection{JUSTIFICACIÓN:}

El conocimiento de la prevalencia de neumonía complicada en niños, resulta importante en primer lugar para las autoridades sanitarias encargadas de la planificación y asignación de recursos institucionales y en segundo lugar para el personal sanitario encargado de tratar estas patologías.

La identificación de las características clínicas de los pacientes con neumonía complicada, se justifica desde el punto de vista social debido a que nos permitirá realizar un diagnóstico y tratamiento oportunos, para de esta manera garantizar la pronta recuperación de nuestros pacientes.

Desde el contexto científico es importante el presente trabajo de investigación ya que en el medio hospitalario en el cuál se realiza el mismo no existen al momento estudios sobre este tema, a pesar de ser una patología frecuente y de que sus complicaciones pueden prolongar la estancia hospitalaria de los pacientes e incluso llevar a la muerte de los mismos.

Md. Verónica Katherine Sánchez Ordóñez 
Además, el estudio realizado servirá como línea de base para el diseño de futuras investigaciones de carácter analítico que aporten al mejor entendimiento de su causalidad para emprender programas dirigidos a la prevención de las complicaciones.

El trabajo realizado se encuentra dentro de las líneas de investigación del Ministerio de Salud Pública 2013-2017, en relación al área 1 de Infecciones comunes, y a línea de infecciones respiratorias bajas.

Los resultados de la presente investigación serán difundidos mediante la revista científica de la Facultad de Ciencias Médicas de la Universidad de Cuenca. 


\section{CAPITULO II}

\subsection{MARCO TEÓRICO}

Definición: es un proceso inflamatorio pulmonar, caracterizado por la consolidación en alveolos debido a microorganismos patógenos. Se define como neumonía adquirida en la comunidad (NAC), cuando el paciente permanece en la comunidad y no ha sido hospitalizado en los últimos 7 días y como neumonía intrahospitalaria (NIH) cuando aparece 48 horas después de su ingreso hospitalario o en los 7 días al alta ${ }^{(9)}$.

Mundialmente representa la primera causa de muerte, y en países desarrollados es una de las primeras causas de morbilidad. La neumonía típica producida por diferentes patógenos, es la causante de la mayor mortalidad y morbilidad de entre los diferentes tipos de neumonía comunitaria ${ }^{(10)}$.

Epidemiología: según la Organización Mundial de la Salud existen alrededor 156 millones de casos de neumonía cada año en menores de 5 años, con al menos 20 millones de casos graves que han necesitado hospitalización. Hay variación en la incidencia y mortalidad por neumonía acorde a la edad, la mayoría hasta $81 \%$ de mortalidad se da en menores de dos años. Mundialmente, las infecciones respiratorias bajas han provocado alrededor de 800.000 muertes en menores de 19 años en el 2015, lo cual representa 31.1 personas por cada 100.000 personas ${ }^{(12)}$. En el mundo, desde hace más de 10 años, hay un aumento de casos de neumonía complicada en niños, mayormente con empiema pleural o necrosis ${ }^{(13)}$.

El derrame pleural en niños es causado principalmente por la neumonía y, aproximadamente, $20-40 \%$ de los ingresos presentan derrame pleural paraneumónico de los cuales, entre 0,6-2\% acaban en empiema. En los últimos años se observaron cambios epidemiológicos aumentando la prevalencia de este tipo de complicaciones. El empiema paraneumónico en niños tiene una incidencia de 1,6/100.000 y la etiología bacteriana (neumococo) es confirmado en la mitad de

Md. Verónica Katherine Sánchez Ordóñez 
los casos. Los casos de neumonías necrotizantes son causadas por empiemas que se han complicado en un $20 \%$ de los casos; siendo su agente causal actualmente en su mayoría el neumococo, siendo antes más común para Stafilococcus aureus (11).

Factores de riesgo: al haber exposición al medio donde se desarrollan los microorganismos, junto con factores de riesgo, la neumonía se puede desarrollar. La literatura menciona como factores definidos entre los cuales se encuentran: malnutrición, bajo peso al nacer, lactancia no exclusiva, ausencia de vacuna contra el sarampión, y la contaminación de los espacios cerrados. Dentro de los probables tenemos el tabaquismo en los padres, deficiencia de zinc, madres primerizas y patologías asociadas. Y los posibles factores: escolaridad de la madre, guarderías, ambientes húmedos, climas fríos, deficiencia de vitamina $A$, orden de nacimiento y contaminación ambiental ${ }^{(12)}$.

Etiología: en todos los grupos etarios la bacteria más común es el S. pneumoniae. La infección por VRS (virus respiratorio sincitial) y rinovirus sobreinfectados con bacterias o solos, son los agentes etiológicos más comunes en menores de 2 años. A partir de los 5 años el Mycoplasma pneumoniae es más común y las infecciones por Clamydia representan la causa más común a partir de los diez años (14).

\section{Clasificación:}

1. Comunitaria: como su nombre lo dice es la que se contrae en el medio comunitario, cuando no ha habido hospitalización previa o cuando en las primeras 48 horas de ingreso hay síntomas relacionados.

2. Nosocomial: es la adquirida durante la hospitalización o 7 días después del alta.

La comunitaria puede ser: bacteriana o típica, provocada por virus y bacterias poco comunes o atípica y no clasificables las que no cumplen criterios de las previas ${ }^{(15)}$. 


\section{Clínica:}

Típica: Se presenta con tos seca al principio, alzas térmicas, hiporexia, y signos de dificultad respiratoria como cianosis, disnea y taquipnea. Suele ir acompañado de dolor torácico pleurítico y expectoración purulenta. Auscultación focal, y en ocasiones soplo tubárico.

Atípica: Se relaciona con Mycoplasma pneumoniae, germen muy frecuente sobre todo en guarderías y escuelas, se caracteriza por antecedentes de contagio con personas infectadas previamente. Su comienzo y clínica es lento y progresivo, con síntomas catarrales, fiebre moderada, tos seca irritativa, y a veces dificultad respiratoria. Auscultación con características bronquiales, que se acompaña de espasticidad. Se acompaña de coriza, conjuntivitis, febrículas y faringitis. En menores de tres meses, la mayoría son provocadas por $C$. trachomatis, la cual se diferencia del resto por cuadros de conjuntivitis y ausencia de fiebre ${ }^{(16,17)}$.

Nosocomial: la característica es que los pacientes presentan progresión de infiltrados previos o infiltrado nuevos, además de leucocitosis o leucopenia, fiebre o hipotermia, incremento en la cantidad y/o purulencia de las secreciones. Además, puede haber desaturación, aumento en los requerimientos de oxígeno, requerimientos de modos ventilatorios y acidosis metabólica ${ }^{(16)}$.

Diagnóstico: está basado en criterios clínicos, radiológicos, epidemiológicos y exámenes complementarios los cuales nos ayudan a identificar el agente causal para dar un tratamiento enfocado y rápido. La mayoría de las veces es necesario realizar estudios serológicos dado que la determinación del agente etiológico para orientar el tratamiento antibiótico es difícil. Mediante el cultivo de líquido pleural o del tejido se determina la etiología de manera efectiva. Al complicarse se realizan pruebas más invasivas: biopsia pulmonar broncoscópica o toracoscópica, cepillado bronquial y lavado broncoalveolar, las mismas que se realizan a niños que ingresan en la UCIP y ventilación mecánica ${ }^{(18)}$.

Md. Verónica Katherine Sánchez Ordóñez 


\section{Complicaciones de la neumonía}

Sepsis y bacteriemia: la bacteriemia no es frecuente en la neumonía neumocócica en niños, se suele complicar la neumonía con sepsis en pacientes con compromiso inmunológico. El Streptococcus pneumoniae es el microorganismo que más provoca cuadros de empiema y neumonía multilobar, y la sepsis grave es mayormente provocada por Staphylococcus aureus, Streptococcus pyogenes y anaerobios ${ }^{(5)}$.

Derrame y empiema: se clasifica en no complicado, complicado y empiema. Dentro de las características del líquido pleural tenemos el no complicado, cuyo ph es mayor a 7.2 con glucosa mayor a $40 \mathrm{mg} / \mathrm{dl}$ y cultivo negativo. El complicado con ph 7.2-7 y/o glucosa menor de 40mg/dl y/o LDH más de 1,000. Y el empiema se caracteriza por presencia de pus libre o ph menor de 7 o cultivo positivo 0 gram positivo (20).

En 24-72 horas evoluciona el derrame pleural paraneumónico, desde un derrame no complicado a una fase inicial exudativa. En el derrame pleural complicado o fase fibrinopurulenta, el líquido se torna más espeso, esto por el aumento de proteínas, haciendo más difícil que drene y formando de esta manera tabiques, todo esto con una duración de más o menos una semana. En la fase organizada hay dificultad en la expansión del tejido debido a la formación de un recubrimiento grueso y sólido el cuál tapiza las pleuras, esta tiene una resolución lenta ${ }^{(19)}$.

Neumonía abscesificada o necrotizante y absceso pulmonar: en la mayoría de estudios publicados el Streptococcus pneumoniae es el principal causante de estas complicaciones. Hallándose relación también con inmunosupresión, malformaciones y broncoaspiraciones. Con menor frecuencia son el Staphylococcus aureus y Streptococcus pyogenes ${ }^{(14)}$.

Se suele acompañar de empiema o derrame pleural complicado. Se suele complicar con la formación de fístulas broncopleurales y neumotórax localizados. Evolucionan favorablemente con drenaje del empiema pleural asociado y antibioterapia. Un

Md. Verónica Katherine Sánchez Ordóñez 
absceso pulmonar se suele observar en la radiografía como cavidades con contenido hidroaéreo, redondas, dispersas en el parénquima. Suele tener una buena evolución con antibióticos ${ }^{(19)}$.

Neumotórax y fístula broncopleural: en la neumonía abscesificada (en algunas series llega al 30-55\%) es frecuente la formación de neumotórax localizados formados por fístulas broncopleurales, haciendo más fácil el colapso del pulmón empeorando la evolución del paciente. También se pueden presentar como complicaciones de procedimientos ${ }^{(5)}$.

Tratamiento: el tratamiento inicial empírico se basa en antibióticos contra los agentes etiológicos más frecuentes, el Staphylococcus aureus y Streptococcus pneumoniae ${ }^{(18)}$.

\section{Tratamiento de las complicaciones:}

Drenaje con tubo pleural: aproximadamente $20-40 \%$ de las NAC ingresadas presentan derrame pleural y de ellas, más de $0,6 \%$ desarrollan empiema. Si las manifestaciones clínicas o el tamaño del derrame es importante, se requiere colocar un tubo de drenaje pleural, caso contrario se suele resolver con antibióticos. Es importante su colocación precoz, en cuanto se llegue al diagnóstico de derrame complicado, ya que posteriormente será difícil ya que en un corto período de tiempo se forman tabiques y es más complejo el drenaje. Se debe colocar un drenaje torácico cuando hallamos en el líquido pleural: pus, Gram positivo, glucosa menos de $50 \mathrm{mg} / \mathrm{dl}$, ph menos de 7 , LDH más de $1000 \mathrm{Ul}$ y compromiso de función pulmonar por derrame extenso que desvía el mediastino (15).

Toracoscopia y videotoracoscopia: es una buena opción con resultados exitosos y mínimos efectos adversos, más opcionado que el tratamiento quirúrgico, esto cuando los antibióticos y el drenaje no han sido efectivos. Cuando hay empiema con abundantes septos y tabicaciones complejas se debería realizar videotoracoscopía Md. Verónica Katherine Sánchez Ordóñez 
(VATS) ya que podría acortar el número de días de fiebre y de ingreso hospitalario. El beneficio principal es la visión óptima de la cavidad pleural lo cual permite un mejor desbridamiento ${ }^{(11)}$.

Decorticación por toracotomía: cuando la toracoscopía no ha sido efectiva, la toracotomía es el tratamiento de elección. Consiste en el drenaje completo de pus así como la eliminación de los tejidos llenos de fibrina. Se trata de un procedimiento efectivo con resultados funcional y morfológicamente y satisfactorios. El tratamiento es muy eficaz, con 90-95\% de resolución de los empiemas ${ }^{(20)}$. 


\section{CAPITULO III}

\subsection{OBJETIVOS:}

\subsubsection{GENERAL:}

Determinar la prevalencia de neumonía complicada en los pacientes hospitalizados del Servicio de Pediatría del Hospital "José Carrasco Arteaga" de la ciudad de Cuenca de enero del 2014 a diciembre del 2017

\subsubsection{ESPECÍFICOS:}

- Caracterizar a la población con neumonía complicada según variables sociodemográficas: edad, sexo y residencia.

- Determinar la frecuencia de variables sociales previas al ingreso tales como: estado nutricional, hacinamiento, comorbilidades respiratorias, cardiacas, renales u otras en la población con neumonía complicada.

- Determinar las variables durante el ingreso hospitalario tales como: días de hospitalización, uso de oxígeno y ventilación mecánica, cirugías y procedimientos practicadas, antibiótico-terapia, sala de hospitalización y condición al egreso en la población con neumonía complicada.

Md. Verónica Katherine Sánchez Ordóñez 


\section{CAPITULO IV.}

METODOLOGIA

\subsection{DISEÑO DE INVESTIGACIÓN:}

\subsubsection{Tipo de Estudio:}

Estudio descriptivo transversal

\subsection{2 Área de Estudio:}

El estudio se realizó en el área de pediatría y UCIP del Hospital "José Carrasco Arteaga" localizado en la avenida Popayán y Pacto Andino. Este hospital pertenece a la parroquia de Monay en la ciudad de Cuenca en el periodo enero del 2014 a diciembre del 2017

\subsubsection{Universo de estudio:}

Total, de pacientes diagnosticados con neumonía en el área de pediatría del Hospital "José Carrasco Arteaga" en el periodo enero del 2014 a diciembre del 2017

\subsubsection{Muestra:}

No se realizó cálculo muestral ya que se trabajó con todos los pacientes diagnosticados con neumonía complicada en el área de pediatría del Hospital "José Carrasco Arteaga" en el periodo enero del 2014 a diciembre del 2017

\subsubsection{Variables en estudio:}

Neumonía complicada y tipo, edad, sexo, residencia, estado nutricional, hacinamiento, comorbilidades respiratorias, cardiacas, renales u otras, días de hospitalización, uso de oxígeno y ventilación mecánica, cirugías y procedimientos practicadas, antibiótico-terapia, sala de hospitalización y condición al egreso.

\subsubsection{Operacionalización de variables:}

Md. Verónica Katherine Sánchez Ordóñez 
Ver Anexo 1

\subsubsection{Criterios de inclusión:}

> Pacientes hospitalizados con diagnóstico de neumonía o que desarrollen una neumonía intrahospitalaria durante su hospitalización, con edades entre 0 y 15 años 11 meses y 29 días, y que presenten cualquier tipo de complicación asociada a la neumonía.

\subsubsection{Criterios de exclusión:}

$>$ Registros incompletos de información.

\subsubsection{Recolección de la información:}

\section{Métodos, Técnicas e Instrumentos}

Luego de la autorización por parte de los directores del Hospital José Carrasco Arteaga se procedió a la recolección de los datos de la historia clínica que consta en el sistema AS400 y en el formulario diseñado por la autora.

Las valoraciones del estado nutricional se llevaron a cabo mediante las curvas estandarizadas de la OMS. En lo que se refiere a hacinamiento se tomó como referencia el índice de hacinamiento utilizado a nivel internacional.

\subsubsection{Aspectos éticos:}

Luego de obtener la aprobación del protocolo por la comisión de bioética de la Facultad de Ciencias Médicas de la Universidad de Cuenca y por parte de las autoridades del Hospital José Carrasco Arteaga, se procedió a la recolección de la información directamente de las historias clínicas, sin interacción con el paciente, por lo cual no se requirió consentimiento informado, respetando la confidencialidad de los datos personales de los participantes, mediante el uso de códigos para cada paciente en lugar del nombre o el número de historia clínica, los mismos que fueron

Md. Verónica Katherine Sánchez Ordóñez 
manejados y revisados únicamente por su autora y director de tesis y se mantendrán en absoluta confidencialidad hasta un año después de su publicación.

Toda la información recolectada fue utilizada únicamente con fines de investigación y publicada en el trabajo de titulación de la autora y productos científicos derivados.

\subsubsection{Plan de Tabulación y Análisis}

\section{Análisis de datos}

Recolectados los datos se procedió a la codificación de los mismos e ingresados en una base de datos en el sistema SPSS versión 15.

Para las variables cualitativas tales como sexo, residencia, exposición a tabaquismo familiar, estado nutricional, hacinamiento, comorbilidades, tipo de complicación, uso de oxígeno y ventilación mecánica, procedimientos y cirugías practicadas, antibióticos recibidos, sala de hospitalización y condición al egreso se obtuvieron frecuencias y porcentajes, a las variables cuantitativas tales como edad, peso, talla y días de hospitalización se las transformó a variables cualitativas para su tabulación.

Para determinar la prevalencia de neumonía complicada se dividió el total de pacientes con complicaciones de la neumonía para el total de pacientes hospitalizados con diagnóstico de neumonía en el mismo periodo de tiempo.

No se declara conflicto de intereses.

Md. Verónica Katherine Sánchez Ordóñez 


\section{CAPITULO V}

\section{RESULTADOS}

\section{Prevalencia:}

La prevalencia de neumonía complicada es de $28,8 \%$.

Tabla 1. Variables sociodemográficas.

\begin{tabular}{cccc}
\hline Variable & & Frecuencia & Porcentaje \\
& & N & $\%$ \\
\hline Sexo & Masculino & 159 & 56,4 \\
& Femenino & 123 & 43,6 \\
& Total & 282 & 100,0 \\
Edad en años & $0-3$ & 153 & 54,2 \\
& $4-6$ & 94 & 33,3 \\
& $7-10$ & 29 & 10,2 \\
Lugar de & $10-14$ & 6 & 2,1 \\
residencia & Total & 282 & 100,0 \\
& Urbana & 166 & 58,9 \\
& Rural & 116 & 41,1 \\
& Total & 282 & 100 \\
\hline
\end{tabular}

Predomina sexo masculino, el grupo etario de 0 a 3 años y la población proviene en su mayoría de la zona urbana.

Tabla 2. Tipo de complicaciones

Md. Verónica Katherine Sánchez Ordóñez 


\begin{tabular}{ccc}
\hline Complicaciones & $\begin{array}{c}\text { Frecuencia } \\
\text { N }\end{array}$ & $\begin{array}{c}\text { Porcentaje } \\
\%\end{array}$ \\
\hline Bacteremia & 122 & 43,2 \\
Empiema & 68 & 24,1 \\
Derrame pleural & 58 & 20,5 \\
Neumotórax & 20 & 7,1 \\
Fistulas & 12 & 4,3 \\
Abscesos & 2 & 0,7 \\
Total & 282 & 100 \\
\hline
\end{tabular}

La complicación de mayor frecuencia es la bacteremia, seguido por el empiema, con una mínima proporción los abscesos.

Tabla 3. Variables previas al ingreso

Md. Verónica Katherine Sánchez Ordóñez 


\begin{tabular}{|c|c|c|c|c|c|}
\hline Variable & & $\begin{array}{c}\text { Frecuencia } \\
\mathbf{N}\end{array}$ & $\begin{array}{c}\text { Porcentaje } \\
\%\end{array}$ & $\begin{array}{c}\text { Frecuencia } \\
\mathbf{N}\end{array}$ & $\begin{array}{c}\text { Porcentaje } \\
\%\end{array}$ \\
\hline & & \multicolumn{2}{|c|}{ Niños } & \multicolumn{2}{|c|}{ Niñas } \\
\hline Estado & Desnutrición & 82 & 51,6 & 62 & 50,4 \\
\hline \multirow[t]{3}{*}{ nutricional } & Normal & 73 & 45,9 & 59 & 48,0 \\
\hline & Sobrepeso & 4 & 2,5 & 2 & 1,6 \\
\hline & Total & 159 & 100,0 & 123 & 100,0 \\
\hline \multirow[t]{3}{*}{ Hacinamiento } & Ausencia & 133 & 83,6 & 100 & 81,3 \\
\hline & Presencia & 26 & 16,4 & 23 & 18,7 \\
\hline & Total & 159 & 100,0 & 123 & 100,0 \\
\hline \multirow[t]{6}{*}{ Comorbilidades } & Ninguna & 118 & 74,2 & 86 & 69,9 \\
\hline & Cardiacas & 19 & 11,9 & 15 & 12,2 \\
\hline & Respiratorias & 17 & 10,7 & 18 & 14,6 \\
\hline & Renales & 4 & 2,5 & 4 & 3,3 \\
\hline & Otros & 1 & 0,6 & 0 & 0,0 \\
\hline & Total & 159 & 100,0 & 123 & 100,0 \\
\hline
\end{tabular}

La desnutrición fue la alteración nutricional más frecuente. La mayoría de pacientes no presentan comorbilidades, de los que si las presentan las más frecuentes fueron las respiratorias. Gran parte de la población en estudio no vive en hacinamiento.

Tabla 4. Variables de estancia hospitalaria

Md. Verónica Katherine Sánchez Ordóñez 


\begin{tabular}{lccc}
\hline Variable & & Frecuencia & Porcentaje \\
& & N & $\%$ \\
\hline Días de & $0-4$ & 39 & 13,8 \\
hospitalización & $5-9$ & 154 & 54,6 \\
& Más de 10 & 89 & 31,5 \\
Sala de & Total & 282 & 100,0 \\
ingreso & General & 232 & 82,3 \\
& Aislamiento & 1 & 0,4 \\
Uso de & UCl & 49 & 49 \\
Oxígeno & Total & 282 & 100,0 \\
& Si & 282 & 100,0 \\
Días de uso de & No & 0 & 0 \\
Oxigeno & Total & 282 & 100,0 \\
& $1-4$ & 136 & 48,2 \\
& $5-9$ & 108 & 38,2 \\
Requerimiento & Más de 10 & 38 & 13,4 \\
de ventilación & Total & 282 & 100,0 \\
mecánica & Si & 57 & 20,2 \\
\hline & No & 225 & 79,8 \\
& Total & 282 & 100,0 \\
\hline
\end{tabular}

La estancia hospitalaria más frecuente fue entre 5 a 9 días, siendo la mayoría de ingresos a sala general. La totalidad de los pacientes requirieron oxigenoterapia, siendo más frecuente su uso entre 1-4 días. Un cuarto de la población requirió apoyo respiratorio mediante ventilación mecánica.

Tabla 5. Procedimientos y cirugías realizados

Md. Verónica Katherine Sánchez Ordóñez 


\begin{tabular}{clcc}
\hline Variable & & Frecuencia & Porcentaje \\
& & N & $\%$ \\
\hline Procedimiento & No & 242 & 85,8 \\
& $\mathrm{Si}$ & 40 & 14,2 \\
& Total & 282 & 100,0 \\
procedimo de & Toracocentesis & 21 & 7,4 \\
& Colocación tubo de & 19 & 6,7 \\
& tórax & & \\
& Ninguna & 242 & 85,8 \\
& Total & 282 & 100,0 \\
& Si & 30 & 10,6 \\
& No & 252 & 89,4 \\
& Total & 282 & 100,0 \\
& Video toracoscopia & 18 & 6,4 \\
& Decorticación & 8 & 2,8 \\
& Lobectomía & 4 & 1,4 \\
& Ninguna & 252 & 89,4 \\
& Total & 282 & 100,0 \\
& & &
\end{tabular}

En la mayor parte de la población no se ejecutó procedimientos invasivos, en los cuales si se realizó, la mayoría fue toracocentesis. Se practicaron cirugías en el $10,6 \%$, en ellos la videotoracospía fue la más frecuente.

\section{Antibioticoterapia administrada}

El antibiótico más utilizado fueron los betalactámicos en el $82,6 \%$ de los pacientes, seguido por los macrólidos en $7.8 \%$, y carbapenémicos en $6.4 \%$, los menos usados fueron los aminoglucósidos en 3.2\%.

Md. Verónica Katherine Sánchez Ordóñez 


\section{Condición de egreso}

Se evidenció un $8.1 \%$ de mortalidad en el estudio.

\section{CAPITULO VI}

\section{DISCUSIÓN}

La prevalencia de neumonía complicada es de $28,8 \%$, lo cual concuerda con lo reportado en la bibliografía en donde refiere que se presenta entre el $20-40 \%$, esto en un estudio realizado en Chile, mientras que en un estudio realizado en el Hospital Universitario de Barcelona señala que aparece en $1 \%$ en la adquirida en la comunidad, pero aumenta hasta $40 \%$ en el ambiente hospitalario. En el Hospital Pediátrico Pepe Portillo de Cuba, en el 2016, se reportó una prevalencia de 51.8\% de neumonías complicadas ingresadas a la Unidad de cuidados intensivos. La diferencia tan significativa con respecto al estudio europeo se puede deber entre otras razones a la falta de protocolos en nuestro medio sobre el tratamiento eficaz y oportuno de las complicaciones de la neumonía ${ }^{(8,11,17)}$.

En este estudio se observa que la neumonía complicada es más frecuente en varones que en las mujeres, encontrando similitud con el estudio realizado en Cuba en el 2016 el cual determina predominio de sexo masculino en casos de neumonía complicada. Se cree que puede deberse a los genes que determinan la cantidad de IgM se ubican en el cromosoma $X$ lo cual justifica que la presencia de un solo cromosoma $X$ favorezca que este sea más susceptible a las infecciones ${ }^{(8)}$.

El grupo etario se concentró entre 0 a 3 años, encontrándose así similitud con Rodríguez Cutting y colaboradores, 2018 quienes plantearon que las infecciones respiratorias continúan siendo un problema importante de salud en los niños menores de 5 años de edad en los países en desarrollo, quienes reportaron mayor frecuencia en el grupo de edades de 1-4 años, esto en posible relación con la inmadurez inmunitaria no alcanzada aún hasta dichas edades ${ }^{(21)}$.

Md. Verónica Katherine Sánchez Ordóñez 
La población proviene en su mayoría de la zona urbana tanto en niños y niñas, este hecho se relaciona a la contaminación ambiental que se generan en las ciudades y a la vinculación precoz a círculos de personas, así como también a situaciones de automedicación y concurrencia a farmacias sin valoraciones médicas previas, es así que al comparar con el estudio realizado en Cuba en el 2018 vemos similitud en los resultados sobre las zonas de las cuales provienen los pacientes ${ }^{(21)}$.

Se observa que cerca la mitad de la población tiene alteración del estado nutricional, siendo la desnutrición la más frecuente y en las niñas se observa más que en los niños, hallándose similitud con un estudio cubano, que reporta el $44 \%$ presentaron desnutrición. Se sabe que al no tener una adecuada reserva proteico-calórica el niño se torna vulnerable para las infecciones ${ }^{(8)}$.

En lo referente al hacinamiento se puede observar que más de dos tercios de la población no viven en condiciones de hacinamiento, lo cual concuerda con dos estudios realizados en Cuba en 2018 en distintos hospitales ${ }^{(25)}$.

Cerca de dos tercios de la población no posee comorbilidades, en la población que si posee se puede observar que las más frecuentes son las respiratorias. Esto concuerda con lo expuesto en el 2016 en Cuba donde se observó que las enfermedades asociadas más comunes fueron las patologías respiratorias, tornando posiblemente al paciente más vulnerable al contagio de patologías infecciosas dado su compromiso a nivel inmunológico ${ }^{(8)}$.

En este estudio se muestra que los días de hospitalización más frecuente fue entre 5 a 9 días y más de dos tercios de la población ingresó a sala general, encontrando similitud con un estudio en Perú en 2018 que indica un predominio en días de hospitalización de 4-6 días, datos que difieren con lo reportado en el 2016 en Paraguay en donde se realizó un estudio observacional, descriptivo de corte transversal en donde se incluyen a escolares 5 a 10 años aquí los días de internación, el $69 \%$ fueron entre 11 a 15 días. Cabe recalcar que la estancia

Md. Verónica Katherine Sánchez Ordóñez 
hospitalaria no se prolongó a pesar de las complicaciones en la mayoría de los pacientes en posible relación con el manejo oportuno o adecuado con la consiguiente resolución de la complicación ${ }^{(22,23) .}$

El antibiótico de mayor utilización son los antibióticos betalactámicos, seguido por macrólidos, datos similares se observan en el estudio de Carranza realizo en Perú en el 2018, al igual que el Consenso de la Sociedad Cubana de Pediatría 2013, quienes recomiendan cefalosporinas de tercera generación, por otro lado, utilizaron la misma medicación en más de la mitad de los pacientes Ardisana Cruz y otros ${ }^{(23,}$ 24). Lamentablemente en la institución no se cuentan con protocolos o guías de práctica clínica actualizadas sobre el manejo de las patologías respiratorias, además no se cuenta la mayor parte del tiempo con toda la medicación necesaria para el tratamiento de los pacientes, por lo cual se utiliza de acuerdo a disponibilidad.

La complicación de mayor frecuencia en pacientes con neumonía complicada dentro del departamento de pediatría del HJCA es la bacteremia, seguido por el empiema, con una mínima proporción los abscesos, que se relaciona con el estudio en La Habana en el 2016 donde reporta dentro de las complicaciones más frecuentes el absceso pulmonar, sin embargo, este dato no coincide con el estudio de Vera y Florentín del 2016 en Paraguay cuya complicación más frecuente fue el

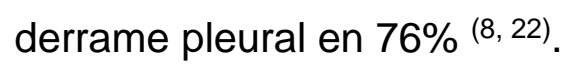

En esta investigación se reportó que se practicaron cirugías en pocos pacientes, en ellos la video-toracoscopía fue la más frecuente, porcentaje menor a lo expuesto en La Habana 2017, en donde la mayoría requirió pleurotomía y en mínima proporción resección pulmonar ${ }^{(23)}$. Según el trabajo realizado en el Hospital Clínico Regional Valdivia se determinó que la videotoracoscopía es la técnica de elección tras la presentación de complicaciones como derrame pleural o tabicaciones tras una neumonía (26).

Md. Verónica Katherine Sánchez Ordóñez 
Se observa que de la población que tuvo neumonía grave cerca de una décima parte de la población falleció $(8,1 \%)$ concuerda con lo reportado en Habana 2017 en donde hubo 9 fallecidos $(5,92 \%)$ (24).

\section{CAPITULO VII CONCLUSIONES}

Md. Verónica Katherine Sánchez Ordóñez 
1. Se determinó una prevalencia alta de neumonía complicada en los pacientes hospitalizados con patología respiratoria en el servicio de pediatría del Hospital José Carrasco Arteaga.

2. El sexo masculino fue el más afectado, al igual que las edades comprendidas entre 0 a 3 años, la mayoría presentaba desnutrición, la patología asociada más común fue la respiratoria.

3. La mayoría de los pacientes permanecieron hospitalizados entre 5-9 días, una cuarta parte de los pacientes necesitaron ventilación mecánica y el antibiótico más utilizado fueron los betaláctamicos. Una mínima cantidad de pacientes requirió procedimientos invasivos y cirugías, entre ellos la toracocentesis y la videotoracoscopía fueron las más comunes.

4. La complicación más común fue la bacteremia y se observó una mortalidad de $8,1 \%$. 


\section{CAPITULO VIII RECOMENDACIONES}

1. Desarrollar protocolos propios de la institución disponibles para médicos tratantes, residentes, posgradistas, personal de enfermería e internos para determinar y estandarizar el manejo adecuado de la neumonía para de esta manera evitar las posibles complicaciones de la misma.

2. Llevar un registro estricto acerca de la epidemiologia de esta patología para futuras investigaciones, para determinar si las cifras de la misma ascienden o descienden, y con este fin determinar acciones.

3. Socializar nuevas guías de práctica clínica, lo más actualizados posible, incentivar la docencia en las unidades de salud, para mantenerse al tanto sobre nuevos tratamientos y recomendaciones sobre el tratamiento de la neumonía.

4. Incentivar el trabajo en equipo entre personal de emergencia pediátrica, clínica y unidad de cuidados intensivos, para de esta manera estandarizar las medidas que se deben tomar cuando el paciente ingresa, durante su hospitalización y en caso de presentarse complicaciones, con el objetivo de mejorar el pronóstico del paciente.

Md. Verónica Katherine Sánchez Ordóñez 


\section{Bibliografía:}

1. World health statistics. Geneva: WHO; 2007. Available from: http://www.who.Int/whosis/whostat2007.

2. Moreno-Pérez, D. y Andrés Martín, A. (2014). Neumonía adquirida en la comunidad: tratamiento ambulatorio y prevención. Anales de Pediatría. [internet]. 2014 [citado agosto 2019];(83):2,3.

3. Marrero M, López M, Sánchez J, Blanco A, Santamaría C, Hernández J. Neumonías Graves y Estado Nutricional en pacientes. Rev Cubana de Medicina Intensiva y Emergencias 2005;4(4) DE: bvs.sld.cu/revistas/mie/vol4_4_05/mie04405.htm

4. Quinde Velastegui José Daniel, Trejo Angulo Nelly Lorena. Neumonía grave en niños menores de 5 años. mayo 2019. http://repositorio.ug.edu.ec/bitstream/redug/43464/1/CD\%202996\%20QUINDE\%20VELASTEGUI\%2C\%20JOS\%C3\%89\%20DANIEL.pdf

5. Rodríguez Y, Mengana E, Farinas A, García Y. Categorización Clínico epidemiológica de pacientes con neumonía grave. Hospital Infantil Norte de Santiago de Cuba. 2012 - 2013.

6. Organización Panamericana de la Salud, Ecuador. Sistema de redes de vigilancia (SIREVA II) http: www.paho.org/ecu

7. Altamirano Palacios, V. Neumonía, factores de riesgo y complicaciones en edad escolar estudio a realizarse en el Hospital Martin Icaza, período 2015. Universidad de Guayaquil; 2015. Disponible en http: //repositorio.ug.edu.ec/bitstream/redug/20325/1/neumonia.pdf

8. Cáceres Roque O, Hernándes García S, Cutiño Miraba L, Gonzalez Lobo E, Días Acosta J. Comportamiento de las neumonías complicadas en niños en Hospital pediátrico provincial pinareño. Revista de Ciencias Médicas de Pinar del Río [Internet]. 2018 [citado Septiembre 2019];(6):2,3,5,6.

9. Cruz J, Dorta Y, Riesgo M, López L, González J. Caracterización clínico epidemiológica de la neumonía en niños hospitalizados. Rev Ciencias Medicas [Internet]. 2012 Feb [citado 2016 Dic 09]; 16(1): 158-168. DE:

Md. Verónica Katherine Sánchez Ordóñez 
scielo.sld.cu/scielo.

php?script=sci_arttext\&pid=S1561-

$31942012000100017 \& \operatorname{lng}=\mathrm{es}$

10. Aracil Santos F. Neumonía complicada. Boletín de la Sociedad de Pediatría de Asturias, Cantabria, Castilla y León [Internet]. 2008 [citado 28 de mayo 2019];(48):183,184,186.

11. Andrés Martín A, Asensio de la Cruz O, Pérez Pérez G. Complicaciones de la neumnía adquirida en la comunidad: derrame pleural, neumonía necrotizante, absceso pulmonar y pioneumotórax. Asociación Española de Pediatría [Internet]. 2020 [citado 2 Octubre 2019];:127,128,133,138,140.

12. Rudan I,Boschi C, Biloglav Z, Mulhollandd K, Campbell H. Epidemiology and etiology of childhood pneumonia. Bulletin of the World Health Organization. May 2008, 86 (5).DOI:10.2471/BLT.07.048769

13. Catacora Sagredo Y. Factores asociados a neumonía complicada Instituto Nacional de Salud del niño 2016 [Especialidad]. Universidad San Martín de Porres; $2019 . \quad$ Disponible en http: http://www.repositorioacademico.usmp.edu.pe/handle/usmp/4908

14. Ubeda Sansano I, Murcia García J, Asensi Monzó T. Neumonía adquiridaen la comunidad. Asociación Española de Pediatría de atención primeria. 2017; $5,6,7$.

15. Rúperez García E, Herranz Aguirre M, Bernaola Iturbe E. Neumonía en el paciente pediátrico. Servicio de Salud pediátrica de Navarra. 2018; 1,2,3.

16. Diagnóstico y tratamiento de la neumonía adquirida en la comunidad en pacientes de 3 meses a 18 años. Guías de Práctica médica. Actualización 2015

17. Inostroza E, Pinto R. Nuevos virus respiratorios en pediatría. Revista médica Clínica Condes [Internet]. 2017. Disponible en DOI: 10.1016/j.rmclc.2017.01.005

18. Moreno Galdó M. Neumonía comunitaria grave. Anales de Pediatría. 2003; (58): 35,36,37

19. Saif $P$, Medina B, Medina B, Mayorga R. Estado nutricional y neumonía grave en pacientes menores de 5 años ingresados en la unidad de cuidados

Md. Verónica Katherine Sánchez Ordóñez 
intensivos del 1 de enero al 31 de diciembre del 2010. Instituto Nacional De Salud del niño. 2011.

20. Moreno-Pérez D, Andrés Martín A, Tagarro García A, Escribano Montaner A, Figerola Mule J, García García J et al. Neumonía adquirida en la comunidad: tratamiento de los casos complicados y en situaciones especiales. Anales de Pediatría [Internet]. 2014 [citado 1 diciembre 2019]: 2,6,7.

21. Rodríguez Cutting J, Vega Mendoza D, Pacheco Torres L, Piedra Bello M, García Sánchez J, Del Valle Rosríguez R. Característiccas clínicas e imagenológicas de niños con neumonía complicada causada por Streptococcus pneumoniae. Revista cunaba de pediatría. 2017; (89): 67,69.

22. Vera Coronel María Belén, Florentín Gladys Damiana. Características clínicas y epidemiológicas de la neumonía complicada en escolares hospitalizados en el Hospital Central del Instituto de Previsión Social, 2016

23. Carranza Berna Gianmarco Amaro. Características clínicas, radiológicas y tratamiento antibiótico de niños menores de 5 años con neumonía adquirida en la comunidad hospitalizados en el servicio de pediatría del Hospital Regional Docente de Cajamarca de enero - diciembre del 2018". Universidad Nacional de Cajamarca

24. Sánchez Infante C, Ramos Carpente L, Reyes López M, Barreiro Paredes B, Cantillo Gámez H, Martínez Silva I. Evolución clínica, aislamiento microbiológico y costo antimicrobiano de la neumonía complicada adquirida en la comunidad. Revista cubana de Pediatría. 2017; (89): 15,16,18,19.

25. Álvarez Andrade M, Hernández Oliva M, Brito Tavares $Y$, Sánchez Pérez L, Cuevas Álvarez D. Riesgo de neumonía grave en niños menores de 5 años. Revista Habanera de Ciencias Médicas. 2018; (3): 410,414,418.

26. Anzieta V., J., Jans B., J., Manoli S., P., Lagos S., L., Cardemil I., C., \& Cerda V., O. (2018). Pleuroneumonías pediátricas en Hospital Clínico Regional Valdivia (HCRV): manejo médico-quirúrgico. Cuadernos de Cirugía, 20(1), 36-42. doi:10.4206/cuad.cir.2006.v20n1-06 
ANEXOS:

1. OPERACIONALIZACIÓN DE VARIABLES:

\begin{tabular}{|c|c|c|c|c|}
\hline VARIABLE & CONCEPTO & DIMENSIÓN & INDICADOR & ESCALA \\
\hline $\begin{array}{l}\text { Edad del } \\
\text { paciente }\end{array}$ & $\begin{array}{l}\text { Tiempo en } \\
\text { meses } \\
\text { transcurrido a } \\
\text { partir del } \\
\text { nacimiento de } \\
\text { un individuo } \\
\text { hasta la fecha } \\
\text { de ingreso al } \\
\text { hospital }\end{array}$ & Cronológica & $\begin{array}{l}\text { Fecha de } \\
\text { nacimiento del } \\
\text { paciente } \\
\text { registrada en } \\
\text { la historia } \\
\text { clínica }\end{array}$ & $\begin{array}{l}\text { Cuantitativa, de razón } \\
\begin{array}{l}\text { 0- } 3 \text { años } \\
4-6 \text { años } \\
7-10 \text { años } \\
10-14 \text { años }\end{array}\end{array}$ \\
\hline Sexo & $\begin{array}{l}\text { Condición } \\
\text { biológica que } \\
\text { define género } \\
\text { según } \\
\text { características }_{\text {fenotípicas }}\end{array}$ & Fenotípica & $\begin{array}{l}\text { Sexo del } \\
\text { paciente } \\
\text { registrado en } \\
\text { la historia } \\
\text { clínica }\end{array}$ & $\begin{array}{l}\text { Cualitativa nominal } \\
\text { dicotómica: } \\
\text { 1. masculino } \\
\text { 2. femenino }\end{array}$ \\
\hline Residencia & $\begin{array}{l}\text { Lugar donde la } \\
\text { persona tiene } \\
\text { su vivienda } \\
\text { habitual por } \\
\text { más de } 5 \text { años }\end{array}$ & Geográfica & $\begin{array}{l}\text { Residencia } \\
\text { registrada en } \\
\text { la historia } \\
\text { clínica }\end{array}$ & $\begin{array}{l}\text { Cualitativa nominal } \\
\text { dicotómica: } \\
\text { 1. urbana } \\
\text { 2. rural }\end{array}$ \\
\hline $\begin{array}{l}\text { Estado } \\
\text { nutricional }\end{array}$ & $\begin{array}{l}\text { Relación del } \\
\text { peso y la talla } \\
\text { para la edad } \\
\text { del paciente de } \\
\text { acuerdo a } \\
\text { curvas } \\
\text { estandarizadas } \\
\text { para la edad. }\end{array}$ & $\begin{array}{l}\text { Antropométric } \\
\text { a }\end{array}$ & $\begin{array}{l}\text { Relación peso } \\
\text { y talla para } \\
\text { edad, peso } \\
\text { para la talla e } \\
\text { IMC, } \\
\text { registrada en } \\
\text { la historia } \\
\text { clínica }\end{array}$ & $\begin{array}{l}\text { Cualitativa ordinal: } \\
\text { - Desnutrición } \\
\text { - Normal } \\
\text { - Sobrepeso } \\
\text { - Obesidad }\end{array}$ \\
\hline
\end{tabular}

Md. Verónica Katherine Sánchez Ordóñez 


\begin{tabular}{|c|c|c|c|c|}
\hline Hacinamiento & $\begin{array}{l}\text { Amontonamien } \\
\text { to o } \\
\text { acumulación } \\
\text { de personas o } \\
\text { animales en un } \\
\text { solo lugar y el } \\
\text { cual no cuenta } \\
\text { con las } \\
\text { dimensiones } \\
\text { físicas para } \\
\text { albergarlos }\end{array}$ & Social & $\begin{array}{l}\text { Valor obtenido } \\
\text { del Índice de } \\
\text { hacinamiento. } \\
=\text { personas } \\
\text { habitando } \\
\text { una vivienda / } \\
\text { número de } \\
\text { dormitorios en } \\
\text { la vivienda, } \\
\text { registrado en la } \\
\text { historia clínica }\end{array}$ & $\begin{array}{l}\text { Cualitativa ordinal: } \\
\text { Hasta } 2_{2}=4 \text { - sin } \\
\text { hacinamiento; } \\
\text { De } 2_{2}=5 \text { a } 4_{2}=9 \text { - } \\
\text { hacinamiento medio } \\
\text { Más de } 5_{2}=0 \\
\text { hacinamiento crítico. }\end{array}$ \\
\hline $\begin{array}{l}\text { Comorbilidade } \\
\text { s respiratorias, } \\
\text { cardíacas, } \\
\text { renales u otras }\end{array}$ & $\begin{array}{l}\text { Patologías } \\
\text { respiratorias, } \\
\text { cardíacas o } \\
\text { renales } \\
\text { previamente } \\
\text { diagnosticadas }\end{array}$ & Clínica & $\begin{array}{l}\text { Diagnóstico } \\
\text { previo de } \\
\text { patologías } \\
\text { respiratorias, } \\
\text { cardíacas, } \\
\text { renales u otras } \\
\text { registrado en } \\
\text { la historia } \\
\text { clínica }\end{array}$ & $\begin{array}{l}\text { Cualitativa nominal } \\
\text { dicotómica: } \\
\text { 1. Si } \\
\text { 2. no } \\
\text { Cualitativa nominal: } \\
\text { Tipo de patología }\end{array}$ \\
\hline $\begin{array}{l}\text { Días de } \\
\text { hospitalización }\end{array}$ & $\begin{array}{l}\text { Días } \\
\text { transcurridos } \\
\text { desde la fecha } \\
\text { de ingreso } \\
\text { hasta la del } \\
\text { alta }\end{array}$ & Cronológica & $\begin{array}{l}\text { Fecha de } \\
\text { ingreso y } \\
\text { fecha de alta } \\
\text { del paciente } \\
\text { registradas en } \\
\text { la historia } \\
\text { clínica }\end{array}$ & $\begin{array}{l}\text { Cuantitativa, de } \\
\text { razón: } \\
0 \text { a } 4 \\
5 \text { a } 9 \\
\text { Más de } 10\end{array}$ \\
\hline $\begin{array}{l}\text { Sala de } \\
\text { ingreso }\end{array}$ & $\begin{array}{l}\text { Lugar donde } \\
\text { fue } \\
\text { hospitalizado el } \\
\text { paciente }\end{array}$ & Clínica & $\begin{array}{l}\text { Registro en la } \\
\text { historia clínica }\end{array}$ & $\begin{array}{l}\text { Cualitativa nominal: } \\
\text { Sala general } \\
\text { Aislamiento } \\
\text { Intensivos }\end{array}$ \\
\hline $\begin{array}{l}\text { Oxígeno } \\
\text { suplementario }\end{array}$ & $\begin{array}{l}\text { Uso de } \\
\text { oxígeno }\end{array}$ & Clínica & $\begin{array}{l}\text { Registro en } \\
\text { historia clínica }\end{array}$ & $\begin{array}{l}\text { Cualitativa nominal } \\
\text { dicotómica: } \\
\text { 1. Si }\end{array}$ \\
\hline
\end{tabular}

Md. Verónica Katherine Sánchez Ordóñez 


\begin{tabular}{|c|c|c|c|c|}
\hline & $\begin{array}{l}\text { durante } \\
\text { hospitalización }\end{array}$ & & & $\begin{array}{l}\text { 2. No } \\
\text { Cuantitativa, de } \\
\text { razón: } \\
\text { Días de uso } \\
\text { 1-4 días } \\
\text { 5-9 días } \\
\text { Más de } 10 \text { días }\end{array}$ \\
\hline $\begin{array}{l}\text { Ventilación } \\
\text { mecánica }\end{array}$ & $\begin{array}{l}\text { Necesidad de } \\
\text { ventilación } \\
\text { mecánica } \\
\text { durante } \\
\text { hospitalización }\end{array}$ & Clínica & $\begin{array}{l}\text { Registro en la } \\
\text { historia clínica }\end{array}$ & $\begin{array}{l}\text { Cualitativa } \\
\text { nominal } \\
\text { dicotómica: } \\
\text { Si } \\
\text { No }\end{array}$ \\
\hline $\begin{array}{l}\text { Antibioticotera } \\
\text { pia }\end{array}$ & $\begin{array}{l}\text { Utilización de } \\
\text { antibióticos } \\
\text { durante } \\
\text { hospitalización }\end{array}$ & Farmacológica & $\begin{array}{l}\text { Registro en la } \\
\text { historia clínica }\end{array}$ & $\begin{array}{l}\text { Cualitativo } \\
\text { nominal: } \\
\text { Betalactámico } \\
\text { s } \\
\text { Penicilinas } \\
\text { Cefalosporinas } \\
\text { Carbapenémic } \\
\text { os } \\
\text { Aminoglucósid } \\
\text { os } \\
\text { Macrólidos } \\
\text { Quinolonas } \\
\text { Otros }\end{array}$ \\
\hline $\begin{array}{l}\text { Procedimiento } \\
\text { s practicados }\end{array}$ & $\begin{array}{l}\text { Procedimientos } \\
\text { que se } \\
\text { realizaron } \\
\text { durante } \\
\text { hospitalización }\end{array}$ & Clínicos & $\begin{array}{l}\text { Registro en } \\
\text { historia clínica }\end{array}$ & $\begin{array}{l}\text { Cualitativa } \\
\text { nominal } \\
\text { dicotómica: } \\
\text { 1. Si } \\
\text { 2. No }\end{array}$ \\
\hline
\end{tabular}

Md. Verónica Katherine Sánchez Ordóñez 


\begin{tabular}{|c|c|c|c|c|}
\hline & & & & $\begin{array}{l}\text { Cualitativa nominal: } \\
\text { Tipo de } \\
\text { procedimiento: } \\
\text { - Colocación de tubo } \\
\text { de tórax } \\
\text { - Punción }\end{array}$ \\
\hline $\begin{array}{l}\text { Cirugías } \\
\text { realizadas }\end{array}$ & $\begin{array}{l}\text { Cirugías que } \\
\text { se realizaron } \\
\text { durante } \\
\text { hospitalización }\end{array}$ & Clínica & $\begin{array}{l}\text { Registro en la } \\
\text { historia clínica }\end{array}$ & 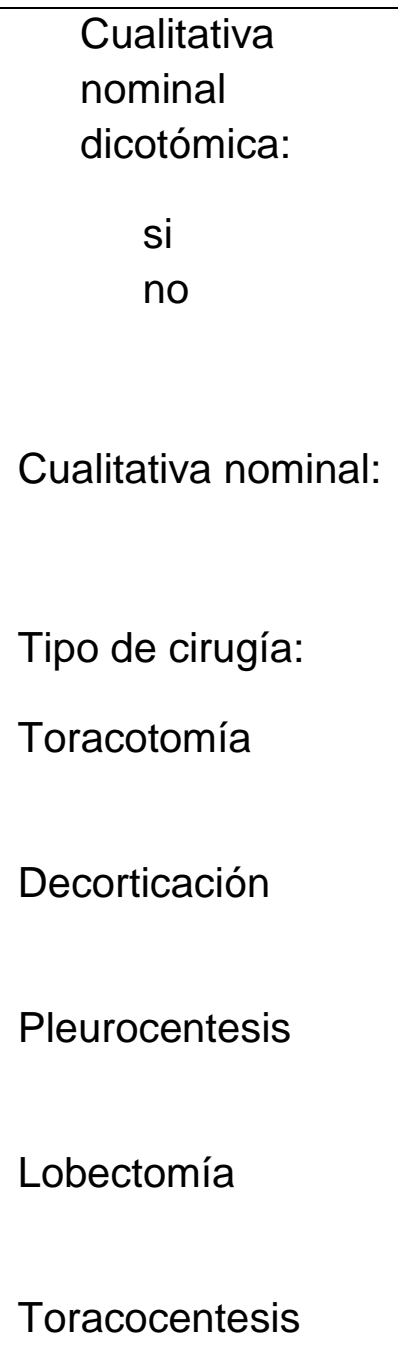 \\
\hline
\end{tabular}




\begin{tabular}{|l|l|l|l|c|}
\hline $\begin{array}{l}\text { Condición al } \\
\text { egreso }\end{array}$ & $\begin{array}{l}\text { Estado en el } \\
\text { que egresa el } \\
\text { paciente de } \\
\text { hospitalización }\end{array}$ & Clínica & $\begin{array}{l}\text { Registro en la } \\
\text { historia clínica }\end{array}$ & $\begin{array}{l}\text { Cualitativa } \\
\text { nominal } \\
\text { dicotómica: }\end{array}$ \\
& & & $\begin{array}{l}\text { vivo } \\
\text { muerto }\end{array}$ \\
\hline
\end{tabular}

ANEXO 2:

TABLA 1: 
DISTRIBUCIÓN DE PACIENTES PEDIÁTRICOS HOSPITALIZADOS CON NEUMONÍA COMPLICADA DE ACUERDO A VARIABLES SOCIODEMOGRÁFICAS. HOSPITAL JOSÉ CARRASCO ARTEAGA 2014 2017.

\begin{tabular}{|l|l|l|l|}
\hline \multicolumn{2}{|c|}{ VARIABLE } & NÚMERO (N) & PORCENTAJE (\%) \\
\hline Edad & $\checkmark$ 0-2 años & & \\
& $\checkmark 2-4$ años & & \\
& $\checkmark 5-9$ años & & \\
& $\checkmark$ 10-15 años & & \\
\hline Sexo & $\checkmark$ Hombre & & \\
& $\checkmark$ Mujer & & \\
\hline Residencia & $\checkmark$ Urbano & & \\
& $\checkmark$ Rural & & \\
\hline
\end{tabular}

TABLA 2:

DISTRIBUCIÓN DE PACIENTES PEDIÁTRICOS HOSPITALIZADOS CON NEUMONÍA COMPLICADA DE ACUERDO A VARIABLES CLÍNICAS. HOSPITAL JOSÉ CARRASCO ARTEAGA 2014 - 2017.

\begin{tabular}{|c|l|l|}
\hline VARIABLE & NÚMERO (N) & PORCENTAJE (\%) \\
\hline Tabaquismo: & & \\
- Si & & \\
\hline Estado nutricional: & & \\
- Desnutrición & & \\
- Normal & & \\
- Sobrepeso & & \\
\hline Hacinamiento: & & \\
- Sin hacinamiento & & \\
- Hacinamiento medio & & \\
- Hacinamiento crónico & & \\
\hline
\end{tabular}

Md. Verónica Katherine Sánchez Ordóñez 


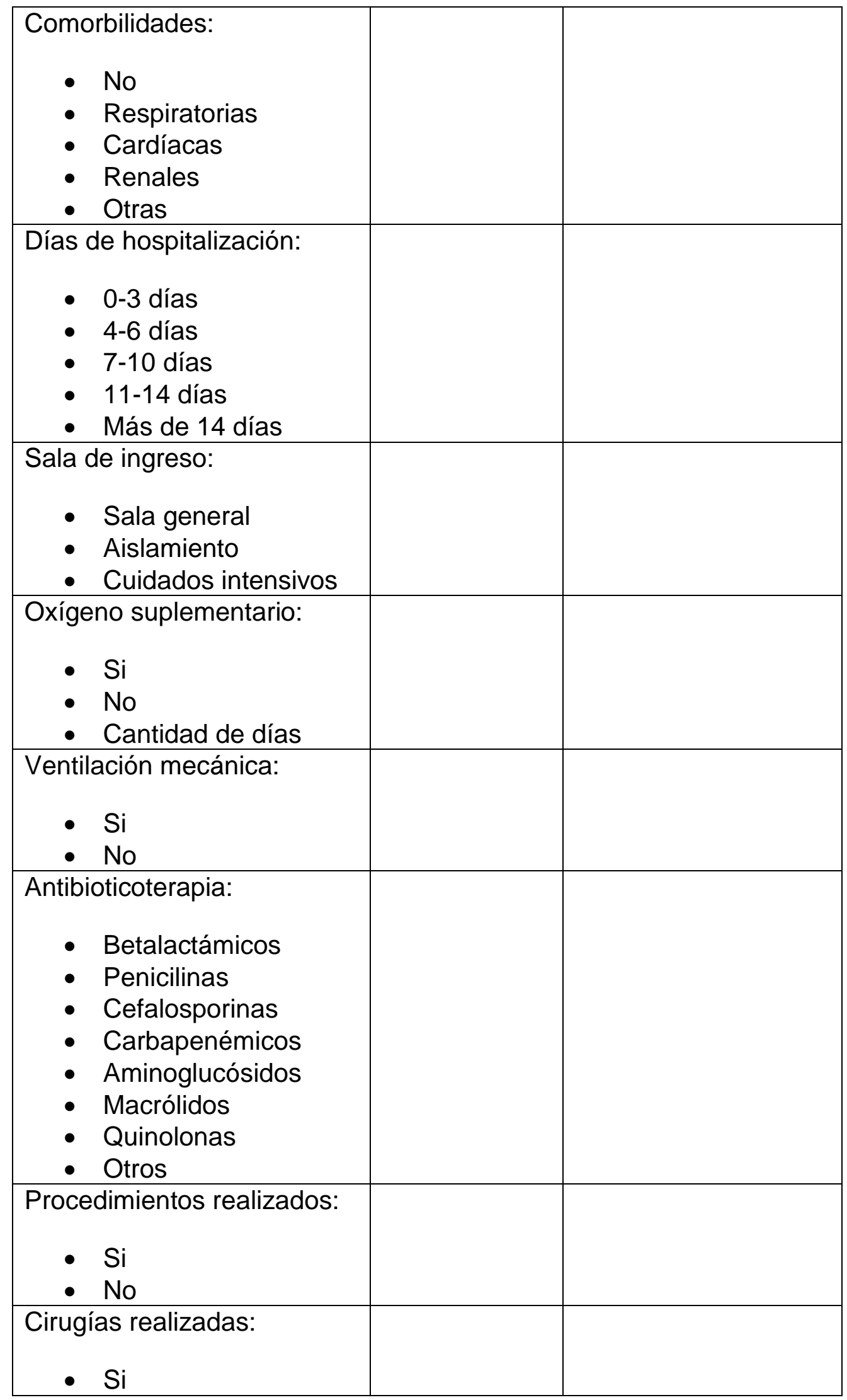

Md. Verónica Katherine Sánchez Ordóñez 


\begin{tabular}{|l|l|l|}
\hline Condición al egreso: & \\
\hline Vivo & & \\
- Muerto & & \\
\hline
\end{tabular}

ANEXO 3

DISTRIBUCIÓN DE LOS PACIENTES PEDIÁTRICOS HOSPITALIZADOS CON NEUMONÍA COMPLICADA DE ACUERDO A TIPO DE COMPLICACIÓN. HOSPITAL JOSÉ CARRASCO ARTEAGA DESDE ENERO DEL 2014 A DICIEMBRE DEL 2017.

\begin{tabular}{|c|c|c|}
\hline \multicolumn{1}{|c|}{ NEUMONÍA } & NUMERO (N) & $\begin{array}{c}\text { PORCENTAJE } \\
(\%)\end{array}$ \\
\hline NO COMPLICADA & & \\
\hline COMPLICADA & \\
- EMPIEMA & \\
- DERRAME PLEURAL & \\
ABSCESO PULMONAR & & \\
- NEPSIS & & \\
\hline
\end{tabular}

Md. Verónica Katherine Sánchez Ordóñez 


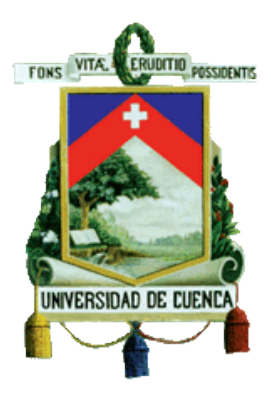

FORMULARIO DE RECOLECCIÓN DE INFORMACIÓN

FACULTAD DE CIENCIAS MÉDICAS DE LA UNIVERSIDAD DE CUENCA.

POSTGRADO DE PEDIATRÍA

\begin{abstract}
"PREVALENCIA DE NEUMONÍA COMPLICADA EN PACIENTES PEDIÁTRICOS HOSPITALIZADOS EN EL HOSPITAL JOSÉ CARRASCO ARTEAGA. ENERO DEL 2014 A DICIEMBRE DEL 2017"
\end{abstract}

Fecha: $\square \square / \square \square / \square \square$ (día, mes, año)

Formulario No.

\title{
DATOS DEL PACIENTE
}

1. EDAD:

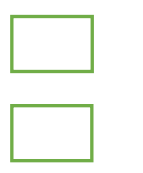

$$
\begin{aligned}
& 0 \text { a } 3 \text { años } \\
& 3 \text { a } 6 \text { años }
\end{aligned}
$$

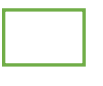

7 a 10 años

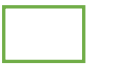

10 a 14 años 
2. SEXO:

$\square$ Masculino
$\square$ Femenino

3. RESIDENCIA:

4. ESTADO NUTRICIONAL:

$\square$ Desnutrición

$\square \quad$ Normal

$\square$ Sobrepeso

$\square$ Obesidad

5. HACINAMIENTO:

$\square$ Sin hacinamiento : 0 a $2_{2}=4$

ए Hacinamiento medio: $2_{2}=5$ a $4_{2}=9$

Hacinamiento crítico: más de $5_{2}=0$

6. COMORBILIDADES:

Cardíacas:

Comunicaciones interventriculares

Md. Verónica Katherine Sánchez Ordóñez 
Comunicaciones interauriculares

Ductus arterioso persistente

Foramen oval

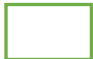

Otras

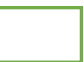

Respiratorias:

Fibrosis quística

Asma

Otras

Renales:

Insuficiencia renal

Hidronefrosis

Enfermedad Poliquística

Malformaciones renales

Otros

7. DÍAS DE HOSPITALIZACIÓN:

$\square \quad 0$ a 4 días

5 a 9 días

Más de 10 días

Md. Verónica Katherine Sánchez Ordóñez 
8. SALA DE INGRESO:

$\square$ Sala general

Aislamiento

$\square$ Cuidados intensivos

9. OXÍGENO SUPLEMENTARIO:

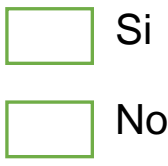

Días de uso:

1-4 días

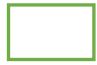

5-9 días

Más de 10 días
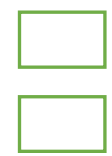

10. VENTILACIÓN MECÁNICA:

$\square \mathrm{Si}$

$\square$ No

11. ANTIBIOTICOTERAPIA:

$\square$ Betalactámicos

Penicilinas

$\square$ Cefalosporinas

$\square$ Carbapenémicos

Md. Verónica Katherine Sánchez Ordóñez 
$\square$ Aminoglucósidos

Macrólidos

$\square$ Quinolonas

$\square$ Otros

12. PROCEDIMIENTOS PRACTICADOS:

$\square \mathrm{Si}$

$\square$ No

Tipo de procedimiento:

13. CIRUGÍAS REALIZADAS:

$\square \mathrm{Si}$

$\square$ No

Tipo de cirugía:

ए Toracotomía

$\square$ Decorticación

$\square$ Pleurocentesis

$\square$ Lobectomía

$\square$ Toracocentesis 
14. CONDICIÓN AL EGRESO:
Vivo
$\square$ Muerto

15. COMPLICACION DE LA NEUMONÍA:

Bacteremia y sepsis

Derrame pleural

Empiema

Abscesos

Fístulas

Neumotórax

Otros
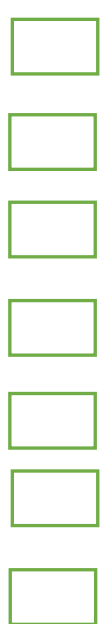